\title{
Chemotherapy and Targeted Therapy Near the end of life Affects Aggressiveness of Palliative Care
}

\section{Wen-Wu Cheng ( $\nabla$ sszyys@163.com )}

Fudan University Shanghai Cancer Center https://orcid.org/0000-0002-0951-7052

\section{Zhe Zhang}

Fudan University Shanghai Cancer Center

\section{Meng-Lei Chen}

Fudan University Shanghai Cancer Center

\section{Xiao-Li Gu}

Fudan University Shanghai Cancer Center

\section{Research article}

Keywords: Cancer, end-of-life, palliative chemotherapy, targeted therapy, aggressiveness of treatment

Posted Date: February 11th, 2020

DOI: https://doi.org/10.21203/rs.2.23123/v1

License: (9) This work is licensed under a Creative Commons Attribution 4.0 International License. Read Full License 


\section{Abstract}

Background: In patients with advanced cancer, considering the increased application of targeted therapy and immunotherapies, we explored the difference between indicators of chemotherapy and targeted therapy in the last month of life.

Methods: Electronic medical data of patients who died from metastatic cancer and received targeted therapy and palliative chemotherapy from April 2007 to December 2018 at the Department of Integrated Therapy, Fudan University Shanghai Cancer Center were analyzed retrospectively. To determine those variables that were judged to be independent predictors of the use of palliative chemotherapy and targeted therapy, and the differences between them, univariate and multivariate analyses were used.

Results: Of the 585 patients included in the study, 87 (14.9\%) received palliative chemotherapy and 125 $(21.3 \%)$ underwent targeted therapy during the last month. Patients who received continued chemotherapy within the last month were subjected to more intensive treatment (admitted to an intensive care unit (ICU) in the last month of life (OR, 2.33; $\mathrm{Cl}$ [1.91-2.92], $\mathrm{P}<0.001)$, and received cardiopulmonary resuscitation(OR, 4.18; $\mathrm{Cl}[2.91-5.40], \mathrm{P}<0.001)$ ), than those who did not. Analysis of subgroups showed that the lung cancer was independently associated with targeted therapy, and admission to an ICU was independently associated with palliative chemotherapy.

Conclusions: Younger patients without complications and with better performance status were more likely to receive chemotherapy. Lower rates of cardiopulmonary resuscitation and admission to ICU correlated with receipt of targeted therapy at the end of life compared with those who received chemotherapy in the last 30 days.

\section{Background}

In the last 20 years, methods to treat cancer have advanced rapidly, with hugely improved anti-cancer efficacy. ${ }^{1}$ However, there is also a growing concern over the aggressiveness of cancer care near the end of life. ${ }^{2,3} \mathrm{~A}$ significant increment in the administration of chemotherapy in the last weeks of life has been observed $^{4-6}$.

When to cease chemotherapy treatment is important for the patients' quality of life (QoL) and is recognized as a quality assurance factor for patients at the end of their life. Earle et al. ${ }^{7}$ suggested that for patients with cancer, indicators for quality of end-of-life palliative care should be identified, and concluded that the continued use of chemotherapy very near to death represented overly aggressive care. Further research has revealed some of the factors associated with palliative chemotherapy. However, factors related to the administration of chemotherapy near the end of life should be investigated further. A Canadian study observed that factors such as cancer type, palliative care assessment, female gender, physician house calls, and utilization of home care, were associated significantly with the decreased use 
of chemotherapy near the end of life. ${ }^{4}$ Furthermore, more aggressive care may be associated with living in an area with higher numbers of teaching hospitals and being cared for in a teaching hospital. ${ }^{8}$

Over the last decade, dramatic changes in the management of patients with advanced cancer have been made. Treatment using palliative chemotherapy treatment (PCT) and the range of available drugs are constantly increasing, including the more frequent use of targeted therapy and immunotherapies. ${ }^{9-10}$ Increased knowledge concerning the molecular events that drive tumorigenesis will lead to more people with advanced cancer receiving targeted therapy.

In the present study, we aimed to contextualize these findings by focusing on patients with advanced cancer who received chemotherapy and targeted therapy during the final month of their lives from April 2007 and December 2018. We explored the percentage of patients with metastatic cancer who were treated using palliative chemotherapy and examined aggressiveness-of-care indicators and the difference between targeted therapy and chemotherapy during the final month of life.

\section{Methods}

The present study used data from the Department of Integrated Therapy in Fudan University Shanghai Cancer Center in Shanghai, China, to construct a retrospective cohort of hospital patients who died from advanced cancer, and received palliative chemotherapy, between April 2007 and December 2018. The Institutional Research Ethics Committee of Fudan University Shanghai Cancer Center approved the study, and prior patient consent was obtained. The following data were collected: sociodemographic information (age, gender, family caregivers, and cancer type); clinical information (performance status (PS), comorbidity, prior treatment, cardiopulmonary resuscitation in the last month of life, $\geq 1$ hospital admission in the last month of life $\geq 1$ intensive care unit (ICU) admission in the last month of life, and endotracheal tube intubation in the last month of life). The exclusion criteria comprised: Patients not seen by the medical oncology service and patients diagnosed with a hematological malignancy.

\section{Data Analyses}

Excel for Windows version 13 (Microsoft Corp., Redmond, WA, https://www.microsoft.com) and SPSS version 20.0 (IBM Corp., Armonk, NY, http://www.ibm.com/) were used to analyze the data. A P $<0.05$ was accepted to indicate statistical significance. Logistic regression modeling was used, the results of which are shown as odds ratios (ORs) and their corresponding $95 \%$ confidence intervals (Cls).

\section{Results}

At the Department of Integrated Therapy in Fudan University Shanghai Cancer Center, 585 patients died of advanced cancer from April 2007 to December 2018 and these patients were enrolled consecutively in the present study. Among them, 87 (14.9\%; 51 (16\%) male and 36 (14\%) female) patients were treated using chemotherapy and 125 (21.3\%) underwent targeted therapy during the last month of life (Table 12). Patients aged less than 50 years old underwent the most EOL chemotherapy $(P<0.001)$ and patients 
whose PS $₫ 2$ were likely to receive targeted therapy and chemotherapy $(P<0.001)$. Among the patients underwent chemotherapy, the most frequently diagnosed cancer was lung cancer (17.6\%), then breast cancer (16.2\%), colorectal cancer (16.1\%), gynecological cancer (12.1\%), gastric cancer (11.4\%), pancreatic cancer $(10.5 \%)$, and other cancers $(18.4 \%)$. The use of palliative chemotherapy in the last month of life was independently associated with age $\leq 50$ years $(O R, 1.78$ [1.28-2.09], $P<0.001)$ and PS $\nabla 2(O R, 2.66[2.14-3.79], P<0.001)$. The use of targeted therapy was independently associated with performance status $<2(\mathrm{OR}, 1.52 ; \mathrm{Cl}[1.15-2.33], \mathrm{P}<0.001)$. (Table 3$)$.

For the indicators of aggressive care, in patients continuing chemotherapy within the last month of life, endotracheal tube intubation near death, ED visit during the last month of life, ICU admission, and CPR were all significantly higher (Table 4). The risk of ICU admission was significantly higher for patients who continued chemotherapy within the last month of life $(\mathrm{OR}, 2.33 ; 95 \% \mathrm{Cl}, 1.91-2.92 ; \mathrm{p}<0.001)$

and these patients more likely to be treated using CPR (OR, 4.18; $95 \% \mathrm{Cl}, 2.91-5.40 ; p<0.001)$ (Table 5).

The differences between targeted therapy and palliative chemotherapy were studied. We found that patients with lung cancer received the most targeted therapy at the terminal stage $(p<0.001)$. We also investigated whether receiving targeted therapy correlated with lower rates of admission to ICU ( $\mathrm{p} \Downarrow .001)$ (Table 6). Logistic regression-based multivariate analysis showed that lung cancer (OR $=4.18 ; 95 \% \mathrm{Cl}$ : $2.29-5.48, \mathrm{p}<0.001)$ was an independent predictor of targeted therapy administration, and admission to an ICU (OR $=2.18 ; 95 \% \mathrm{Cl}: 1.81-2.75)$ was an independent predictor of palliative chemotherapy administration (Table. 7).

\section{Discussion}

The present study investigated the situation of EOL chemotherapy and targeted therapy in patients at the end of life using consecutive data from 585 patients with advanced cancer who had died of cancer at our center. We showed that receipt of targeted therapy correlated with lower rates of admission to ICU compared with those who received palliative chemotherapy.

At the end of life, more detailed conversations between physicians and caregivers and patients could reduce the incidence of aggressive treatment, resulting in a significantly better QoL in the last month of life. ${ }^{11}$ However, for patients who are dying from advanced solid tumors, decision making in terms of treatment at the end of life is complex. Deciding upon a more aggressive intervention involves not only access to a hospice, but also the knowledge and attitude of the patient and their family toward hospices and palliative chemotherapy, and their relationship with primary and specialist physicians. Unfortunately, administrative data does not include these preferences.

Generally, certain physicians from cancer-specialty hospitals have studied palliative guidelines systematically. However, physicians can overestimate prognosis, often by at least $30 \% .{ }^{12}$ Some physicians are from general hospitals and lack professional palliative knowledge, and it is difficult for many oncologists and caregivers to provide the option of stopping chemotherapy. ${ }^{13,14}$ Hesitation 
regarding cessation of futile palliative chemotherapy might lead to more aggressive EOL care and lifesustaining treatment. In China, some caregivers ask physicians not to tell the truth concerning the patient's condition, such that patients fail to receive the full picture regarding their disease and do not understand the purpose of palliative care, believing that their disease is curable. ${ }^{15}$ Patients have high expectations of palliative therapy and thus accept the adverse events and toxicity to prolong their survival. ${ }^{16}$ Previous studies found that patients would prefer to receive chemotherapy, even if it only prolonged their life for 1 week, because most patients do not receive enough information concerning the benefits of palliative chemotherapy. ${ }^{17}$

Our study showed that in the last month of life, about $14.9 \%$ of patients received palliative chemotherapy, which is in line with international recommendations. However, a Portuguese study indicated that the prevalence of chemotherapy within the last month of life could be as high as $37 \% .^{18}$ One reason is that in more affluent countries, patients have a high chance of receiving medicalized death and futile treatments. ${ }^{19}$ Another explanation is that, at the end of life, older patients in China are more inclined to receive Chinese medicine rather than western medicine, which would affect the low proportion of chemotherapy use.

The results of the present study showed that younger patients ( $<50$ years old) with a PS $₫ 2$ received more aggressive EOL chemotherapy and targeted therapy. There are several potential explanations for this. Patients younger than 50 years old were mostly better educated and tended to choose western medicine in preference to traditional Chinese medicine, which could explain why this subgroup were more likely to receive palliative chemotherapy. The younger patients also had lower rates of comorbidity and received more rounds of cytotoxic chemotherapy. There is a complex relationship between relationship aggressive care and comorbidity. Patients with comorbid conditions were less prone to receiving chemotherapy, and if they did receive it, they were more likely to be admitted to ICU or go to hospital in the final month of life. ${ }^{20}$

Admission to an ICU and receipt of CPR were more frequent among patients treated with palliative chemotherapy than in patients who received targeted therapy in the last month of life. Previously, the therapeutic options for patients with advanced cancer were limited to cytotoxic chemotherapy. Over the last decade, the treatment of patients with, for example, advanced NSCLC, has changed markedly. Successful therapies that target patients with anaplastic lymphoma kinase (ALK) rearrangements or epidermal growth factor receptor (EGFR) mutations have been developed. ${ }^{21-23}$ In cases where a specific oncogenic driver gene has been identified, most people choose targeted therapy. Thus, targeted therapy was used more often than traditional chemotherapy agents which often have lower toxicity and fewer complication, and our study results showed that patients who received targeted therapy received less aggressive treatment, such as ICU admissions and CPR treatment.

Every individual at the EOL has a right to pursue life prolongation at any cost. We cannot consider that their aggressive care is not necessary. However, mounting evidence suggests that the majority of dying patients do not desire such care. ${ }^{24-26}$ Research also suggests that less aggressive care is cheaper and 
less upsetting for surviving members of the patient's family. ${ }^{27-30}$ Accordingly, the arguments in favor of less aggressive EOL care suggest that discussions about changing EOL care should occur earlier to ensure that palliative treatment is consistent with the patient's preferences.

Using these data as a starting point, we hypothesized that the adverse events or toxicity associated with intravenous chemotherapy outweigh its benefit over the whole course of treatment, especially toward the EOL. Considering the increasing availability of targeted therapy, we require a deeper understanding of their role at the EOL. In addition, we lack detailed knowledge about the factors that affect chemotherapy decision making at the EOL among physicians, patients, and their caregivers, such as, the effects of the values and beliefs of the patients and physicians, and discussion about decision making on the use of care at EOL. These factors will also contribute to the reason of their choice at EOL, for example emergency department visits, admission to an intensive care unit, increased hospital admission, or decreased hospice use. ${ }^{31}$

\section{Limitations}

One limitation is the retrospective nature of this study, which relied on hospital records. A further limitation is that we did not analyze the role of targeted therapy at the EOL stage, which needs more research. In addition, a detailed analysis of the relationship between palliative chemotherapy and survival data of patients was not performed.

\section{Conclusions}

The present study explored the prevalence of the application of targeted therapy and palliative chemotherapy in Chinese patients with solid cancers. During their last month of life, $14.9 \%$ of patients with advanced cancer received chemotherapy and $21.3 \%$ underwent targeted therapy, which was similar to that reported in other studies. Most patients receiving palliative chemotherapy preferentially received cardiopulmonary resuscitation and admission to ICU compared with patients receiving targeted therapy; however, the role of targeted therapy requires further study. China requires further palliative care guidelines to enhance the quality of EOL care.

\section{Declarations}

\section{Declaration of Conflicting Interests}

The authors declared no potential conflicts of interest with respect to the research, authorship, and/or publication of this article.

\section{Funding}

The authors received no financial support for the research, authorship, and/or publication of this article. 


\section{References}

1. Dizon DS, Krilov L, Cohen E et al. Clinical cancer advances 2016: annual report on progress against cancer from the American Society of Clinical Oncology. J Clin Oncol 2016; 34(9): 987-1011.

2. Earle CC, Landrum MB, Souza JM et al. Aggressiveness of cancer care near the end of life: is it a quality-of-care issue? J Clin Oncol 2008;26(23): 3860-3866.

3. Martoni AA, Tanneberger S, Mutri V. Cancer chemotherapy near the end of life: the time has come to set guidelines for its appropriate use. Tumori 2007; 93(5): 417-422.

4. Earle CC, Neville B. a, Landrum MB et al. Trends in the aggressiveness of cancer care near the end of life. J Clin Oncol 2004; 22(2): 315-321.

5. Ho TH, Barbera L, Saskin R et al. Trends in the aggressiveness of end-of-life cancer care in the universal health care system of Ontario, Canada. J Clin Oncol 2011; 29(12): 1587-1591.

6. Liu T-W, Chang W-C, Wang H-M et al. Use of chemotherapy at the end of life among Taiwanese cancer decedents, 2001-2006. Acta Oncol 2012; 51(4): 505-511.

7. Earle CC, Park ER, Lai B et al. Identifying potential indicators of the quality of end-of-life cancer care from administrative data. J Clin Oncol 2003; 21:1133-1138.

8. Earle CC, Landrum MB, Souza JM et al. Aggressiveness of cancer care near the end of life: is it a quality-of-care issue? J Clin Oncol 2008; 26: 2860-2866.

9. Naylor EC, Desani JK, Chung PK. Targeted Therapy and Immunotherapy for Lung Cancer. Surg Oncol Clin N Am 2016, 25:601-609.

10. Guan LY, Lu Y. New developments in molecular targeted therapy of ovarian cancer. Discov Med.2018 Nov;26(144):219-229.

11. Zhang B, Wright AA, Huskamp $\mathrm{H}$ A et al. Health care costs in the last week of life: Associations with end-of-life conversation s. Arch Intern Med 2009; 169:480- 488.

12. Glare $\mathrm{P}$, Virik $\mathrm{K}$, Jones $\mathrm{M}$ et al. A systematic review of physicians' survival predictions in terminally ill cancer patients. BMJ 2003; 327:195-198.

13. The AM, Hak T, Koeter $\mathrm{G}$ et al. Collusion in doctor-patient communication about imminent death: An ethnographic study. West J Med 2001; 174:247-253.

14. Cavalli-Bjorkman N, Glimelius B, Strang P. Equal cancer treatment regardless of education level and family support? A qualitative study of oncologists' decision-making. BMJ 0 pen 2012;2:e001248.

15. Temel JS, Greer JA, Admane S et al. Longitudinal perceptions of prognosis and goals of therapy in patients with metastatic non-small-cell lung cancer: Results of a randomized study of early palliative care. J Clin Oncol 2011; 29:2319-2326.

16. Patnaik A, Doyle C, Oza AM. Palliative therapy in advanced ovarian cancer: Balancing patient expectations, quality of life and cost. Anticancer Drugs 1998; 9:869- 878.

17. Wright AA, Zhang B, Keating NL et al. Associations between palliative chemotherapy and adult cancer patients' end of life care and place of death: Prospective cohort study. BMJ 2014; 348:g1219. 
18. Braga S, Miranda A, Fonseca R et al. The aggressiveness of cancer care in the last three months of life: A retrospective single centre analysis. Psychooncology 2007; 16:863-868.

19. Goh CR. Medicalization of dying: Are we turning the corner? J Palliat Med 2012; 15:728-729.

20. Earle CC, Neville BA, Landrum MB et al. Trends in the Aggressiveness of Cancer Care Near the End of Life. J Clin Oncol.2004. Jan 15;22(2):315-21.

21. Bild AH, Yao G, Chang JT e t al. Oncogenic pathway signatures in human cancers as a guide to targeted therapies. Nature 2006; 439:35 3-357.

22. Pao W, Chmielecki J. Rational, biologically based treatment of EGFR-mutant non-small-cell lung cancer. Nat Rev Cancer 2010;10:760-774.

23. Tseng HH, He B. Molecular markers as therapeutic targets in lung cancer. Chin J Cancer 2013; 32:59-62.

24. Wright AA, Zhang B, Ray A, et al: Associations between end-of-life discussions, patient mental health, medical care near death, and caregiver bereavement adjustment. JAMA 2008,300:1665-1673

25. Mack JW, Weeks JC, Wright AA, et al: End-of-life discussions, goal attainment, and distress at the end of life: Predictors and outcomes of receipt of care consistent with preferences. J Clin Oncol 2010,28:1203-1208

26. Weeks JC, Cook EF, O'Day SJ, et al: Relation-ship between cancer patients' predictions of prognosis and their treatment preferences. JAMA 1998, 279: 1709-1714

27. Zhang B, Wright AA, Huskamp HA, et al: Health care costs in the last week of life: Associations with end-of-life conversations. Arch Intern Med 2009,169:480-488

28. Brumley R, Enguidanos S, Jamison P, et al: Increased satisfaction with care and lower costs: Results of a randomized trial of in-home palliative care. J Am Geriatr Soc 2007,55:993-1000

29. Gade G, Venohr I, Conner D, et al: Impact of an inpatient palliative care team: A randomized control trial. J Palliat Med 2008,11:180-190

30. Wright AA, Keating NL, Balboni TA, et al: Place of death: Correlations with quality of life of patients with cancer and predictors of bereaved caregivers' mental health. J Clin Oncol 2010,28:4457-4464.

31. Fang $P$, Jagsi $R, H e$ W, et al: Rising and Falling Trends in the Use of Chemotherapy and Targeted Therapy Near End of Life in Older Patients With Cancer. J Clin Oncol.2019 Jul 10;37(20):1721-1731.

\section{Tables}


Table 1. Baseline characteristics of the patients receiving chemotherapy included in the study $(\mathrm{N}=585)$

Chemotherapy within the last month of life, no. (\%ם

\begin{tabular}{|c|c|c|c|c|}
\hline Characteristics & $\begin{array}{c}\text { Total } \\
585\end{array}$ & $\begin{array}{c}\text { YES } \\
87\end{array}$ & $\begin{array}{c}\text { NO } \\
498\end{array}$ & $\mathrm{p}$ value \\
\hline \multicolumn{5}{|l|}{ Age } \\
\hline$\leq 50$ & 55 & 18ロ0.33ロ & 37ロ0.67ロ & 00.001 \\
\hline $50-59$ & 142 & $21 \square 0.15 \square$ & 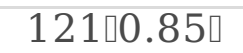 & \\
\hline $60-69$ & 249 & 33ロ0.14】 & $216 \square 0.86 \square$ & \\
\hline $70-79$ & 79 & 110.16ロ & $68 \square 0.84 \square$ & \\
\hline$\geq 80$ & 60 & $2 \llbracket 0.04 \square$ & $58 \square 0.96 \square$ & \\
\hline \multicolumn{5}{|l|}{ Gender } \\
\hline Male & 320 & 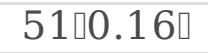 & $269(0.84)$ & 0.722 \\
\hline Female & 265 & $36 \square 0.14 \square$ & $229(0.86)$ & \\
\hline \multicolumn{5}{|l|}{ Family caregivers } \\
\hline Son or daughter & 153 & $29(0.16)$ & $124(0.84)$ & \\
\hline Spouse & 221 & $33(0.15)$ & $188(0.85)$ & \\
\hline Others & 211 & $25(0.12)$ & $186(0.88)$ & \\
\hline \multicolumn{5}{|l|}{ Prior treatment } \\
\hline First line & 102 & $18(0.18)$ & $84(0.82)$ & 0.042 \\
\hline Second line & 198 & $30(0.15)$ & $168(0.85)$ & \\
\hline Third line & 190 & $30(0.16)$ & $160(0.84 \square$ & \\
\hline Fourth line or more & 95 & $9(0.09)$ & $86(0.91)$ & \\
\hline \multicolumn{5}{|l|}{ Cancer type } \\
\hline Lung cancer & 148 & $25(0.17)$ & $122(0.83)$ & 0.632 \\
\hline Breast cancer & 113 & $16(0.15)$ & $97(0.85)$ & \\
\hline Colorectal cancer & 85 & $14(0.16)$ & $71(0.84)$ & \\
\hline Gynecological cancer & 59 & $7(0.12)$ & $52(0.88)$ & \\
\hline Gastric cancer & 50 & $5(0.11)$ & $45(0.89)$ & \\
\hline Pancreatic cancer & 32 & $3(0.10)$ & $29(0.90)$ & \\
\hline Others & 98 & $17(0.18)$ & $81(0.82)$ & \\
\hline With comorbidity & & & & 0.026 \\
\hline YES & 373 & $67(0.18)$ & $306(0.82)$ & \\
\hline NO & 212 & $20(0.09)$ & $192(0.91)$ & \\
\hline \multicolumn{5}{|l|}{ Performance status } \\
\hline 0 & 105 & $29(0.28)$ & $76(0.82)$ & $\square 0.001$ \\
\hline 1 & 142 & $21(0.15)$ & $121(0.85)$ & \\
\hline$\geq 2$ & 338 & $38(0.11)$ & $301(0.89)$ & \\
\hline
\end{tabular}


Table 2. Baseline characteristics of the patients receiving targeted therapy included in the study $(\mathrm{N}=585)$ targeted therapy within the last month of life, no. (\%ם

\begin{tabular}{|c|c|c|c|c|}
\hline Characteristics & Total & YES & NO & $\mathrm{p}$ value \\
\hline & 585 & 125 & 460 & \\
\hline Age & & & & 0.214 \\
\hline$\leq 50$ & 55 & $17 \llbracket 0.30 \square$ & $38 \square 0.70 \square$ & \\
\hline $50-59$ & 142 & $34 \square 0.24 \square$ & 108ロ0.76ロ & \\
\hline $60-69$ & 249 & $54 \llbracket 0.22 \square$ & 195ロ0.78ロ & \\
\hline $70-79$ & 79 & $14 \square 0.18 \square$ & 65ロ0.82ロ & \\
\hline$\geq 80$ & 60 & $6 \square 0.10 \square$ & $54 \llbracket 0.90 \square$ & \\
\hline Gender & & & & 0.473 \\
\hline Male & 320 & $68 \square 0.21 \square$ & $252(0.79)$ & \\
\hline Female & 265 & 57ロ0.22ロ & $208(0.78)$ & \\
\hline Family caregivers & & & & 0.060 \\
\hline Son or daughter & 153 & $46(0.30)$ & $107(0.70)$ & \\
\hline Spouse & 221 & $36(0.16)$ & $185(0.84)$ & \\
\hline Others & 211 & $43(0.20)$ & $168(0.80)$ & \\
\hline With comorbidity & & & & 0.021 \\
\hline YES & 373 & $84(0.22)$ & $289(0.78)$ & \\
\hline NO & 212 & $41(0.19)$ & $171(0.81)$ & \\
\hline \multicolumn{5}{|l|}{ Performance status } \\
\hline 0 & 105 & $40(0.38)$ & $65(0.62)$ & $\square 0.001$ \\
\hline 1 & 142 & $25(0.17)$ & $117(0.73)$ & \\
\hline$\geq 2$ & 338 & $60(0.18)$ & $278(0.82)$ & \\
\hline
\end{tabular}

Table 3. Multiple Logistic Regression Analysis for Chemotherapy and targeted therapy within the last month of life affecting aggressiveness of end -of-life care $(n=585)$

Variable

Chemotherapy

targeted therapy

OR $(95 \%$ CI $)$

OR $(95 \%$

CI)

Age(years) $\leq 50$ (reference, 050 )

$1.78(1.28-2.09)$

NO

Performance status $\square 2$ (reference, $\geq 2$ )

$2.66(2.14-3.79)$

1.52

(1.15-2.33)

Abbreviations: CI, confidence interval; OR, odds ratio.

The logistic regression analysis with stepwise selection methods whose covariates (all of which were significant in univariate analyses) included patient age, prior treatment, with comorbidity, and performance status. 
Table 4. Associations between palliative chemotherapy and indicators of aggressive care Chemotherapy within the last month of life, no. (\%)

\begin{tabular}{lcccc}
\hline Aggressiveness-of-care characteristics & & YES & NO & p value \\
$\geq 1$ Hospital admissions in last month & 328 & $55(0.16)$ & $273(0.84)$ & 0.792 \\
YES & 257 & $32(0.12)$ & $225(0.88)$ & \\
NO & 278 & $46(0.17)$ & $232(0.83)$ & 0.633 \\
$\geq 1$ Hospital admissions (LOS $>14$ d) in last month & 307 & $41(0.13)$ & $266(0.87)$ & \\
YES & 22 & $10(0.45)$ & $12(0.55)$ & $\square 0.001$ \\
NO & 563 & $77(0.14)$ & $486(0.86)$ & \\
$\geq 1$ ICU admissions in last month & & & & \\
YES & 62 & $15(0.24)$ & $47(0.76)$ & $\square 0.001$ \\
NO & 523 & $72(0.14)$ & $451(0.86)$ & \\
$>1$ ED visits in last month & & & & \\
YES & 116 & $32(0.27)$ & $84(0.73)$ & $\square 0.001$ \\
NO & 469 & $55(0.12)$ & $409(0.88)$ & \\
Received CPR & 18 & $25(0.22)$ & $14(0.78)$ & $\square 0.001$ \\
YES & 567 & $62(0.11)$ & $497(0.86)$ & \\
NO & & &
\end{tabular}

Table 5. Multiple Logistic Regression Analysis for associations between palliative chemotherapy and indicators of aggressive care within the last month of life

Variable Chemotherapy within the last month of life OR $(95 \%$ CI)

$\geq 1$ ICU admission in the last month (reference, $<1$ ) $2.33(1.91-$ 2.92)

Received cardiopulmonary resuscitation (reference, No) $4.18(2.91-$ 5.40)

Abbreviations: CI, confidence interval; OR, odds ratio. The logistic regression analysis with stepwise selection methods whose covariates (all of which were significant in univariate analyses) included $\geq 1$ ICU admission in the last month, $>1$ ED visit in the last month, and received cardiopulmonary resuscitation and endotracheal tube intubation. 
Table 6. Aggressiveness-of-care indicators and difference between targeted therapy and chemotherapy within the last month of life

Characteristics

Targeted
therapy in the
last month $\begin{gathered}\text { in the last } \\ \text { month }\end{gathered}$

$\geq 1$ Hospital

87

admissions in last

month

YES

68

55

0.235

NO

57

32

$\geq 1$ Hospital

admissions (LOS > 14

d) in last month

YES

75

46

0.672

NO

50

41

$\geq 1$ ICU admissions in

last month

YES

20

10

$\square 0.001$

NO

105

77

$>1 \mathrm{ED}$ visits in last

month

YES

36

15

0.028

NO

89

72

Received CPR

YES

13

112

32

0.021

NO

Endotracheal tube

intubation

YES

12

25

$\square 0.001$

NO

113

62

Cancer type

Lung cancer

Breast cancer

42

21

Others

62

13

$\square 0.001$

18

56

Table 7. Aggressiveness-of-care indicators and difference between targeted therapy and chemotherapy within the last month of life.

Variable

Targeted therapy

Chemotherapy

OR $(95 \% \mathrm{CI})$

OR

$(95 \%$ CI $)$

Lung cancer (reference, other types of cancer ${ }^{*}$ )

$4.18(2.29-5.48)$

$\geq 1$ ICU admissions in last month (reference, $<1$ )

(1.81-2.75) 

Abbreviations: CI, confidence interval; OR, odds ratio.
The logistic regression analysis with stepwise selection methods whose covariates (all of which were significant in univariate analyses) included $\geq 1$ ICU admission in the last month, $>1$ ED visit in the last month, and received cardiopulmonary resuscitation and endotracheal tube intubation.
*other types of cancer included breast cancer, colorectal cancer, gynecological cancer, gastric cancer, and other. 